\title{
Роль хронического воспалительного процесса в прогрессировании атеросклероза у пациентов с хронической обструктивной болезнью легких в сочетании с артериальной гипертонией
}

Кафедра внутренних болезней ГОУ ВПО "Кировская государственная медицинская академия Росздрава": 610027, Киров, ул. Карла Маркса, 112

\author{
O.V.Milutina, E.N.Chicherina
}

\section{Role of chronic inflammation for atherosclerosis progression in patients with chronic obstructive pulmonary disease and hypertension}

\begin{abstract}
Summary
The purpose of the present trial was to study impact of Simvastatin on CRP and intima-media complex thickness of the common carotid arteries in patients with COPD and concurrent hypertension. Twelve patients with COPD and concurrent hypertension were studied and 21 patients were included in the control group. CR and plasma lipids were measured and Doppler echocardiography of vessels was performed. After 6 months of treatment with Simvastatin, CRP level and the intima-media complex thickness of the common carotid arteries have been significantly reduced. Key words: chronic obstructive pulmonary disease, hypertension, C-reactive protein, intima-media complex thickness of the common carotid arteries.
\end{abstract}

\section{Резюме}

Целью исследования явилось изучение влияния симвастатина на уровень С-реактивного белка (СРБ) и толщину комплекса интима-медиа (КИМ) общих сонных артерий у больных хронической обструктивной болезнью легких (ХОБЛ) в сочетании с артериальной гипертонией (АГ). Были обследованы 12 больных ХОБЛ в сочетании с АГ и 21 пациент из группы сравнения. Проведены допплерографическое исследование сосудов, определение уровня СРБ, оценка липидного спектра. На фоне лечения симвастатином у больных ХОБЛ в сочетании с АГ в течение 6 мес. получена достоверная динамика снижения уровня СРБ и толщины КИМ общих сонных артерий.

Ключевые слова: хроническая обструктивная болезнь легких, артериальная гипертония, С-реактивный белок, комплекс интима-медиа общих сонных артерий.

В основе хронической обструктивной болезни легких (ХОБЛ) лежит хронический воспалительный процесс в бронхиальном дереве, нарушающий целостность эпителиального пласта и обусловливающий запуск бронхоконстрикторных реакций [1]. Его развитие во многом определяется состоянием иммунной системы.

Маркерами системного воспаления при ХОБЛ являются С-реактивный белок (СРБ), фибриноген, нейтрофилы периферической крови, провоспалительные цитокины интерлейкин- $1 \beta$ (IL-1 $\beta$ ), интерлейкин-6 (IL-6), фактор некроза опухоли- $\alpha$ (TNF- $\alpha$ ), хемокин интерлейкин-8 (IL-8) и др. [2]. При ХОБЛ уровень этих маркеров увеличивается не только в легких, но и в периферической крови, что указывает на системное воспаление [3]. Содержание СРБ, фибриноген и TNF- $\alpha$ при стабильной ХОБЛ оказывается значительно более повышенным, по сравнению со здоровыми лицами [4, 5]. W.Q.Gan et al. отметили рост уровня сывороточного СРБ у пациентов с ХОБЛ и выявили его связь с риском развития кардиоваскулярных событий [6]. СРБ является наиболее изученным маркером воспаления. Высокая концентрация системных маркеров воспаления ассоциирована с атеросклерозом и его осложнениями [7]. Во мно- гих исследованиях показано активное участие СРБ в развитии атеросклероза [8], однако остается неясным, играет ли он прямую или опосредованную роль в прогрессировании атеросклероза. СРБ, являясь основным белком воспаления, может усиливать продукцию других цитокинов, активировать систему комплемента, стимулировать захват липопротеидов низкой плотности (ЛПНП) макрофагами, усиливать адгезию лейкоцитов сосудистым эндотелием, т. е. увеличивать воспалительный каскад [9]. Все эти изменения ведут к воспалению, нестабильности атеромы, вазоконстрикции и тромбообразованию.

Таким образом, информативность показателя СРБ, определенного высокочувствительными методами, выше, чем у холестерина и ЛПНП. Риск сердечно-сосудистых осложнений у пациентов с повышением уровня СРБ возрастает по мере увеличения содержания других факторов риска (холестерина, фибриногена, гомоцистеина и др.). Согласно данным Фрамингеймского исследования (2003), концентрации СРБ $<1$ мг/л, $1-3$ мг/л и $>3$ мг/л соответствуют низкому, умеренному и высокому риску развития сердечно-сосудистых заболеваний [10].

И.В.Тихонова и соавт. обнаружили, что в сыворотке крови больных ХОБЛ в стадии обострения 
происходит многократное (в 10-500 раз) увеличение концентрации провоспалительных цитокинов (IL-1 $\beta$, TNF- $\alpha$, интерферона- $\gamma$ ) по сравнению с условно здоровыми исследуемыми, а концентрация СРБ повышается в 2-3 раза. Значительно возрастает количество десквамированных эндотелиальных клеток в крови, что свидетельствует об остром характере воспалительного процесса, сопровождающегося нарушением эндотелиальной функции сосудов. В стадии ремиссии происходит достоверное снижение маркеров воспаления, однако оно остается значительно выше нормы, что свидетельствует о персистенции скрытого хронического воспаления в респираторной системе [11]. Следовательно, повышение СРБ у больных ХОБЛ, особенно при тяжелом течении, связано с повышенным риском развития кардиальных событий.

Цель данной работы - изучить влияние симвастатина на системное воспаление и состояние эндотелия общих сонных артерий у больных ХОБЛ в сочетании с АГ.

\section{Материалы и методы}

Обследованы 12 пациентов (6 мужчин и 6 женщин) с ХОБЛ I-II стадий (GOLD, 2006) в фазе ремиссии в сочетании с АГ. Средний возраст составил 62,1 \pm 9,1 года, стаж ХОБЛ - 11,4 \pm 7,0 лет, стаж АГ - 13,5 \pm 6,2 года. Для контроля были набраны 3 группы сравнения. 1-ю группу составили 11 пациентов с изолированным течением АГ (средний возраст $-47,5 \pm 8,4$ года, стаж АГ - 5,4 \pm 4,4 года), 2-ю - 10 больных с изолированной ХОБЛ (средний возраст $-51,8 \pm$ 4,6 года, стаж ХОБЛ - 12,7 \pm 5,9 года). В 3-ю группу были включены 10 практически здоровых лиц, не имевших сердечно-сосудистых и бронхолегочных заболеваний (средний возраст - 49,6 \pm 5,3 года).

Из исследования были исключены пациенты с III стадией АГ, симптоматической АГ, хронической сердечной недостаточностью III-IV функциональных классов, всеми клиническими формами ишемической болезни сердца, декомпенсированным легочным сердцем, сахарным диабетом, печеночной и почечной недостаточностью, нарушением мозгового кровообращения.
Всем пациентам энзиматическим колориметрическим методом определяли уровень общего холестерина (ОХС), триглицеридов (ТГ), холестерин липопротеидов высокой плотности (ХСлпвп). Содержание липопротеидов низкой плотности (ЛПНП) вычисляли по формуле Фривальда:

$$
\begin{aligned}
& \mathrm{XC} \text { лпнп }_{\text {O }} \mathrm{OXC}-\left(\mathrm{XC}_{\text {лпвп }}+\mathrm{XC}_{\text {лпонп }}\right) \text {, } \\
& \mathrm{XC}_{\text {лпонп }}=\mathrm{T} \Gamma \times 0,46 \text {, } \\
& \text { ИА }=(O X C-X C \times \text { ЛПВП) } / \text { ХC } \times \text { ЛПВП, }
\end{aligned}
$$

где ХСлпонп - холестерин липопротеидов очень высокой плотности, ИА - индекс атерогенности.

У всех больных ХОБЛ в сочетании с АГ было выявлено повышение уровня ОХС до 5,0 \pm 0,8 ммоль/л, и поэтому на фоне гипотензивной терапии (лизиноприл в дозе 2,5-10 мг в сутки) они в течение 6 мес. получали симвастатин в дозе 20 мг в сутки.

У всех пациентов оценивали толщину комлекса интима-медиа (КИМ) общих сонных артерий и уровня СРБ как исходно, так и через 3 и 6 мес. терапии симвастатином.

Уровень СРБ определяли количественным методом на аппарате Integra-700 (Cobas Integra Roche, Швейцария) в интервале от 1 до 10 мг/л (турбидиметрический метод). Толщину КИМ измеряли в области бифуркации общей сонной артерии с правой и левой стороны на аппарате Philips En Vizor (США) линейным датчиком с частотой 7 МГц.

Статистическую обработку результатов проводили с помощью программ Microsoft Excel и Biostat. Достоверность результатов лечения оценивали при помощи критерия Стьюдента.

\section{Результаты и обсуждение}

Достоверных различий показателей липидного спектра, полученных методом ферментного анализа, у больных ХОБЛ в сочетании с АГ и в группах сравнения выявлено не было (табл. 1), но следует подчеркнуть, что ИА во всех обследуемых группах был выше границ условной нормы $(>3,0)$, включая группу контроля.

Анализ уровня СРБ показал, что у больных с изолированным течением АГ его значение составило

Сравнительный анализ показателей Таблица 1 у больных ХОБЛ и АГ

\begin{tabular}{|l|c|c|c|c|c|}
\multicolumn{1}{r|}{ Показатель } & Контроль $(n=10)$ & АГ $(n=11)$ & ХОБл $(n=10)$ & ХОБл и АГ $(n=12)$ & $p$ \\
\hline ОХС, ммоль/л & $4,5 \pm 1,1$ & $5,2 \pm 1,3$ & $4,9 \pm 0,8$ & $5,0 \pm 0,8$ & 0,773 \\
\hline ТГ, ммоль/л & $1,4 \pm 0,5$ & $1,8 \pm 1,0$ & $1,8 \pm 0,9$ & $2,2 \pm 1,8$ & 0,531 \\
\hline ХСлпвп, моль/л & $1,2 \pm 0,4$ & $1,0 \pm 0,4$ & $1,0 \pm 0,4$ & $1,2 \pm 0,5$ & 0,320 \\
\hline ХСлпн, Ммоль/л & $2,6 \pm 1,2$ & $3,4 \pm 1,1$ & $3,1 \pm 0,7$ & $2,9 \pm 1,1$ & 0,625 \\
\hline ХСлппн, ммоль/л & $0,7 \pm 0,2$ & $0,8 \pm 0,5$ & $0,8 \pm 0,4$ & $1,1 \pm 0,9$ & 0,342 \\
\hline ИА & $3,1 \pm 1,7$ & $4,1 \pm 1,6$ & $4,6 \pm 1,7$ & $5,1 \pm 2,1^{*}$ & 0,552 \\
\hline СРБ, мг/л & $0,7 \pm 0,1$ & $1,7 \pm 0,8^{*}$ & $6,8 \pm 1,2^{*},{ }^{*}$ & $7,0 \pm 5,9^{*}, * *$ & 0,917 \\
\hline КИМ, см & $0,7 \pm 0,1$ & $0,7 \pm 0,1$ & $0,8 \pm 0,2$ & $1,0 \pm 0,2^{*, * *}$ & $0,030^{*}$ \\
\hline
\end{tabular}

Примечание: * - достоверность различий между показателями контрольной группы и группами сравнения; ** - достоверность различий между показателями группы с изолированным течением АГ и группой с изолированным течением ХОБЛ; $p$ - достоверность различий между показателями в группе с изолированным течением ХОБЛ и в группе ХОБЛ в сочетании с АГ. 
$1,7 \pm 0,8$ мг/л, что достоверно выше, чем у здоровых лиц $(0,7 \pm 0,1$ мг/л; $p<0,0001)$. У больных с изолированным течением ХОБЛ концентрация СРБ достигала $6,8 \pm 1,2$ мг/л, а при сочетании ХОБЛ с АГ - 7,0 \pm 5,9 мг/л. При этом выявлено высокодостоверное повышение уровня СРБ при изолированном течении ХОБЛ $(p<0,0001)$ и при сочетании ХОБЛ с АГ $(p=0,003)$, в сравнении со здоровыми лицами, а также с пациентами с изолированным течением АГ ( $p<0,0001$ и $p=0,008$ соответственно). Следует отметить, что значения СРБ в группе с изолированным течением ХОБЛ и сочетанной патологией ХОБЛ и АГ были сопоставимы ( $p=0,917)$. Таким образом, судя по уровню СРБ, пациенты с ХОБЛ находятся в группе высокого риска развития сердечно-сосудистых событий.

Толщина КИМ общих сонных артерий была достоверно больше у больных ХОБЛ в сочетании с АГ, в сравнении как с группой контроля $(p<0,001)$, так и с группами с изолированным течением АГ $(p<0,001)$ и ХОБЛ $(p=0,030)$.

Ультразвуковое исследование общих сонных артерий выявило стенозирование просвета общих сонных артерий до 20-35 \% у $33 \%$ больных ХОБЛ в сочетании с АГ. При изолированном течении ХОБЛ таких пациентов было $20 \%(p=0,198)$. У больных АГ изолированного течения при допплерографии сосудов таких изменений не выявлено.

В ходе корреляционного анализа установлена прямая достоверная зависимость между повышением уровня СРБ и толщиной КИМ у больных с сочетанием ХОБЛ и АГ $(p=0,05)$, а у больных с изолированным течением ХОБЛ данная связь отсутствовала $(p=0,174)$.

Лечение симвастатином в дозе 20 мг в сутки все больные ХОБЛ в сочетании с АГ переносили хорошо, побочных явлений не наблюдалось ни у одного из них. Достоверного снижения показателей липидного спектра на фоне 6-месячной терапии не произошло (табл. 2).

В то же время уже через 3 мес. терапии у пациентов с сочетанной патологией уровень СРБ снижался до 2,13 $\pm 2,29$ мг/л $(p=0,05)$, а через 6 мес. лечения до $1,65 \pm 0,21$ мг/л $(p=0,040)$. Применение симва-

Таблица 2

Влияние симвастатина на показатели липидного спектра, уровень СРБ и КИМ общих сонных артерий у больных ХОБЛ в сочетании с АI

\begin{tabular}{|c|c|c|c|}
\hline Показатель & Исходно & Через 3 мес. & Через 6 мес. \\
\hline ОХС, ммоль/л & $5,0 \pm 0,8$ & $5,0 \pm 1,6$ & $4,8 \pm 1,2$ \\
\hline ТГ, ммоль/л & $2,2 \pm 1,8$ & $1,7 \pm 1,4$ & $1,5 \pm 0,8$ \\
\hline ХС Спвп, ммоль/л & $1,2 \pm 0,5$ & $1,2 \pm 0,4$ & $1,1 \pm 0,3$ \\
\hline ХС & $2,9 \pm 1,1$ & $3,03 \pm 1,1$ & $3,0 \pm 1,5$ \\
\hline ХСлпонп, ммоль/л & $1,1 \pm 0,9$ & $0,8 \pm 0,7$ & $0,6 \pm 0,4$ \\
\hline ИА & $5,1 \pm 2,1$ & $3,6 \pm 2,2$ & $3,5 \pm 1,8$ \\
\hline СРБ, мг/л & $7,0 \pm 5,9$ & $2,13 \pm 2,29^{*}$ & $1,65 \pm 0,21^{* *}$ \\
\hline КИМ, см & $1,0 \pm 0,2$ & $1,02 \pm 0,56$ & $0,89 \pm 0,29^{* *}$ \\
\hline
\end{tabular}

Примечание: * - достоверность различий между показателями до лечения симвастатином и через 3 мес. терапии, ${ }^{* *}$ - достоверность различий между результатами до лечения симвастатином и через 6 мес. терапии. статина сопровождалось уменьшением толщины КИМ общих сонных артерий через 3 мес. терапии до $1,02 \pm 0,56$ см $(p=0,078)$, а через 6 мес. - достоверным ее сокращением до $0,89 \pm 0,29$ см $(p=0,018)$.

Как известно, инициирующим фактором развития атеросклеротического процесса является первичное повреждение эндотелия, которое морфологически характеризуется нарушением цитоскелета, ослаблением межклеточных связей, изменением расстояния между клетками [12]. Важными факторами первичного повреждения эндотелия являются бактериальная и вирусная инфекции и сопутствующие им клеточные и гуморальные иммунные и / или аутоиммунные реакции, вызывающие воспалительные изменения в сосудистой стенке [13].

\section{Заключение}

1. Течение ХОБЛ в сочетании с АГ сопровождается повышением уровня СРБ, что является свидетельством системного воспаления, которое вызывает прогрессирование атеросклероза.

2. Применение симвастатина уже в дозе 20 мг в сутки у больных ХОБЛ в сочетании с АГ достоверно уменьшает уровень СРБ и толщину КИМ общих сонных артерий, тем самым снижая риск сердечно-сосудистых событий при данной сочетанной патологии.

\section{Литература}

1. Barnes P.J. Mediators of chronic obstructive pulmonary disease. Pharmacol. Rev. 2004; 56: 515-548.

2. Wouters E.F.M. The systemic face of airway diseases: the role of C-reactive protein. Eur. Respir. J. 2006; 27: 877-879.

3. Agusti A.G.N., Noguera A., Sauleda J. et al. Systemic effects of chronic obstructive pulmonary disease. Eur. Respir. 2003; 21: $347-360$.

4. Gan W.Q., Man S.F., Senthilselvan A. et al. Association between chronic obstructive pulmonary disease and systemic inflammation: a systematic review and a meta-analysis. Thorax 2004; 59: 574-580.

5. Sin D.D., Man S.F. Why are patients with chronic obstructive pulmonary disease at increased risk of cardiovascular diseases? The potential role of systemic inflammation in chronic obstructive pulmonary disease. Circulation 2003; 107: 1514-1519.

6. Gan W.Q., Paul Man S.F., Sin D.D. The interactions between cigarette smoking and reduced lung function on systemic inflammation. Chest 2005; 127: 558-564.

7. Lind L. Circulating markers of inflammation and atherosclerosis. Atherosclerosis 2003; 169: 203-214.

8. Kinlay S., Selwyn A.P. Effects of statins on inflammation in patients with acute and chronic coronary syndromes. Am. J. Cardiol. 2003; 91 (suppl. 4A): 9B-13B.

9. Verma S., Li S.H., Badiwala M. V. et al. Endothelin antagonism and interleukin- 6 inhibition attenuate the proatherogenic effects of C-reactive protein. Circulation 2002; 105: 1890-1896.

10. Ridker P.M., Buring J.E., Cook N.R., Rifai N. C-reactive protein, the metabolic syndrome, and risk of incident cardiovascular events: an 8-year follow-up of 14719 initially healthy American women. Circulation 2003; 107: 391-397. 
Милютина О.В., Чичерина Е.Н. Роль хронического воспалительного процесса в прогрессировании атеросклероза

11. Тихонова И.В., Танканаг А.В., Косякова Н.И. и др. Изменение уровня маркеров воспаления и состояние периферического кровотока в микроциркуляторном русле кожи у больных хронической обструктивной болезнью легких. Пульмонология 2008; 1: 57-61.

12. Stary H.C., Chandler A.B., Glagov S. et al. A definition of initial, fatty streak, and intermediate lesions of atherosclerosis: a report from the Committee on Vascular Lesions of the Council on Atherosclerosis, American Heart Association. Special report. Arterioscler Tromb 1994; 14: 840-856.
13. Gurevich V.S. Influenza autoimmunity and atherogenesis. Autoimmun. Rev. 2005; 4 (2): 101-105.

\section{Информация об авторах}

Милютина Ольга Васильевна - ассистент кафедры внутренних болезней Кировской государственной медицинской академии; тел.: (332) 60-40-38

Чичерина Елена Николаевна - д. м. н., проф., зав. кафедрой внутренних болезней Кировской государственной медицинской академии; тел.: (332) 60-40-38

Поступила 27.03.09

(с) Милютина О.В. Чичерина Е.Н., 2009 удК 616.24-036.12-06:616.13-004.6 